\title{
Oversikt over helseregistre i Norge
}

\author{
Inger Cappelen og Heidi Lyshol \\ Avdeling for helsestatistikk, Nasjonalt folkehelseinstitutt, Postboks 4404 Nydalen, 0403 Oslo \\ Korrespondanse: Inger Cappelen, E-post: inger.cappelen@fhi.no Telefon: 23408157
}

\begin{abstract}
SAMMENDRAG
Systemet med unike fødselsnumre i Norge gjør datasettet som er tilgjengelig om den norske befolkningen nokså omfattende. Denne artikkelen beskriver hovedregistrene over helseinformasjon i Norge, inkludert registrene som er regulert av forskrifter. Disse omfatter registre over dødsårsaker, kreftsykdom, fødselsutfall, smittsomme sykdommer, barnevaksiner og resepter utløst ved apoteker. De medisinske kvalitetsregistrene omfatter bl.a. informasjon om leddproteser, barnediabetes og multippel sklerose. Det norske pasientregisteret inneholder alle data om sykehusutskrivninger etter diagnose. En annen viktig gruppe av registre er forskningsregistrene som forvaltes av Nasjonalt folkehelseinstitutt.
\end{abstract}

Cappelen I, Lyshol H. An Overview of the Health Registers in Norway. Nor J Epidemiol 2004; 14

(1): $33-38$.

\section{ENGLISH SUMMARY}

The system of unique identifying numbers used in Norway makes the set of data available about the Norwegian population quite comprehensive. This article describes the main registers on health information in Norway, including the registers regulated by the Personal Health Data Filing System Act, on causes of death, cancer, birth outcome, infectious diseases, childhood vaccinations and prescriptions dispensed from pharmacies. The medical quality registers include information about joint replacements, childhood diabetes and multiple sclerosis. The Norwegian Patient Register includes all data on hospital discharges by diagnosis. Another important group of registers are the research registers situated at the Norwegian Institute of Public Health.

\section{Sentrale helSEREgiSTRE}

Sentrale helseregistre er opprettet av den sentrale helseforvaltning og er hjemlet $i$ Lov om helseregistre og behandling av helseopplysninger (Helseregisterloven) av 18.05.2001 som trådte i kraft 01.01.2002. I $\S 8$ i helseregisterloven er seks helseregistre spesielt nevnt og disse har hver sin forskrift. I disse seks registrene kan navn, fødselsnummer og andre direkte personidentifiserende kjennetegn behandles uten samtykke fra den registrerte. I tillegg er det kommet et nytt helseregister (Reseptbasert legemiddelregister) der helseopplysningene behandles i pseudonymisert form. Disse syv registrene beskrives nærmere nedenfor.

\subsection{Dødsårsaksregisteret}

Databehandlingsansvarlig: Nasjonalt folkehelseinstitutt.

Databehandler: Statistisk sentralbyrå (SSB) som har vært driftsansvarlig siden 1926.

Hjemmel: Dødsårsaksforskriften av 21. desember $2001 \mathrm{nr} .1476$.

Generell beskrivelse: Alle dødsfall som registreres danner grunnlag for den årlige dødårsaksstatistikken fra SSB, med formål å overvåke dødsårsaker og belyse endringer over tid. I registeret finnes hovedsakelig opplysninger om dødsårsak i tillegg til informasjon om hvor døden inntraff (hjemme, under arbeid, sykehus osv.).

Kjennetegn: Fullt fødselsnummer.

Forste og siste år det finnes data for: 1951-2002.

Antall poster: Totalt ca. 2 mill. poster, ca. 45000 nye tilfeller per år.

Oppdatering: Årlig, publiseres noe over 1 år etter det aktuelle år.

Innsamling: Dødsårsaksstatistikken utarbeides på grunnlag av dødsmeldinger fra offentlige leger. I tillegg innhentes opplysninger fra Kreftregisteret, Medisinsk fødselsregister, statistikk over veitrafikkulykker og resultater av obduksjoner fra sykehus og rettsmedisinske undersøkelser.

Utvalg: Statistikken omfatter alle døde som på dødstidspunktet var registrert som bosatt i Norge, uansett om dødsfallet fant sted i Norge eller utenfor landets grenser.

Tilgang til data: Reviderte retningslinjer for tilgang til data er under utarbeidelse.

Soknad sendes til: Statistisk sentralbyrå, PB 8131 Dep, 0033 Oslo.

Web-adresse: www.ssb.no/emner/03/01/10/dodsarsak. 


\subsection{Kreftregisteret}

Databehandlingsansvarlig: Kreftregisteret. Databehandler: Kreftregisteret, opprettet i 1951. Hjemmel: Kreftregisterforskriften av 21. desember 2001 nr. 1477.

Generell beskrivelse: Kreftregisteret skal både samle inn alle tilfeller av kreft, og samle inn data for personer som deltar i kreftundersøkelser. Årsstatistikken skal kartlegge kreftsykdommenes utbredelse i Norge og belyse endringer over tid.

Kjennetegn: Fullt fødselsnummer der det er mulig.

Forste og siste år det finnes data for: 1953-2000. Data fra 2001 blir offentliggjort i 2004.

Antall poster: Totalt ca. 930000 poster, ca. 23000 nye tilfeller i året.

Oppdatering: Årlig, publiseres ca. 2 år etter det aktuelle år.

Innsamling: Kreftregisteret mottar meldinger om kreft fra flere kilder. Alle sykehus og patologiske laboratorier har plikt til å melde kreftsykdom på fastsatt skjema. Videre mottar Kreftregisteret meldinger om dødsfall med kreftdiagnose fra SSB.

Utvalg: Statistikken omfatter alle som får kreft og som er bosatt i Norge, uansett om krefttilfellet ble oppdaget i Norge eller utenfor landets grenser.

Tilgang til data: Etter retningslinjene i Kreftregisterforskriften.

Soknad sendes til: Kreftregisteret, Montebello, 0310

Oslo.

Web-adresse: $\underline{\text { ww.kreftregisteret.no. }}$

\subsection{Medisinsk fødselsregister}

Databehandlingsansvarlig: Nasjonalt folkehelseinstitutt.

Databehandler: Medisinsk fødselsregister (organisert som avdeling ved Folkehelseinstituttet).

Hjemmel: Medisinsk fødselsregisterforskrift av 21. desember 2001 nr. 1483.

Generell beskrivelse: MFR driver forskning og overvåking av helseforhold knyttet til svangerskap og fødsel. Formålet er å overvåke medfødte misdannelser og etablere databaser for studier av perinatale helseproblemer. I tillegg skal registeret utføre oppgaver knyttet til tilsyn med og kvalitetssikring av helsetjenester for gravide, fødende og nyfødte. Registeret har vært i drift fra 1967 og har opparbeidet seg en sentral plass i norsk og internasjonal epidemiologisk forskning. I miljøet som er bygget opp rundt MFR drives flere store forskningsprosjekt og mindre registre.

Kjennetegn: Fullt fødselsnummer.

Forste og siste år det finnes data for: 1967-2002.

Antall poster: ca. 2200000 poster totalt, ca. 60000 fødsler per år.

Oppdatering: Årlig, publiseres påfølgende år.

Innsamling: Helsepersonell som bistår ved fødsel, på sykehus eller annet sted, plikter i henhold til forskrift å sende meldeskjema om fødsler og fødselsutfall. Pilot- prosjekt med elektronisk innrapportering er i gang.

Utvalg: Statistikken omfatter alle fødsler og fødselsutfall i Norge etter 12. svangerskapsuke. Innrapportering av svangerskapsavbrudd etter 12. svangerskapsuke og svangerskap etter utført IVF/ICSI er også omfattet av forskriften (egne skjema).

Tilgang til data: Etter retningslinjer i forskriften, samt Publikasjonsutvalget ved MFR (www.uib.no/mfr/).

Soknad sendes til: Medisinsk fødselsregister, Kalfarveien 31, 5018 Bergen.

Web-adresse: www.uib.no/mfr/.

\subsection{Meldingssystem for smittsomme sykdommer (MSIS)}

Databehandlingsansvarlig: Nasjonalt folkehelseinstitutt.

Databehandler: Nasjonalt folkehelseinstitutt.

Hjemmel: MSIS og tuberkuloseforskriften av 20. juni 2003 nr. 740.

Generell beskrivelse: MSIS skal bidra til overvåkingen av smittsomme sykdommer hos mennesker i Norge, og legge grunnlaget for å:

1. beskrive forekomsten av smittsomme sykdommer over tid og etter geografiske og demografiske forhold,

2. oppdage og bidra til oppklaring av utbrudd av smittsomme sykdommer,

3. gi råd til publikum, helsepersonell og forvaltning om smitteverntiltak,

4. evaluere virkninger av smitteverntiltak og

5. drive, fremme og gi grunnlag for forskning om smittsomme sykdommers utbredelse og årsaker.

Kjennetegn: Fullt fødselsnummer for sykdommer $i$ gruppe A: Difteri, Kikhoste, Kusma, Meslinger, Poliomyelitt, Røde hunder, Systemisk Haemophilus influenzae-sykdom, Tetanus (Stivkrampe), Tuberkulose, Hepatitt A, Hepatitt B, Hepatitt C, Botulisme, Campylobacteriose, E.coli-enteritt, Giardiasis, Listeriose, Salmonellose, Yersiniose, Brucellose, Ekinokokkose, Lyme borreliose, Miltbrann, Nephropathia epidemica, Rabies, Trikinose, Tularemi, Flekktyfus, Gulfeber, Hemoragisk feber, Kolera, Lepra, Malaria, Pest, Shigellose, Tilbakefallsfeber, Atypisk mykobakterieinfeksjon, Legionellose, AIDS, SARS (Alvorlig, akutt luftveissyndrom), Encefalitt, Kopper, Paratyfoidfeber, Prionsykdommer, Systemisk meningokokksykdom, Systemisk pneumokokksykdom, Systemisk gruppe A streptokokksykdom, Systemisk gruppe B streptokokksykdom, Tyfoidfeber, Infeksjoner med meticillinresistente gule stafylokokker, Infeksjoner med penicillinresistente pneumokokker og Infeksjoner med vankomycinresistente enterokokker.

Bare fødselsmåned og -år og kjønn for sykdommer $i$ gruppe B: Gonoré, Syfilis og HIV-infeksjon.

Forste og siste år det finnes data for: 1977-2003. Fødselsnummeropplysningene er mangelfulle for mange årganger og poster.

Antall poster: ca. 150000. 
Oppdatering: For mange sykdommer publiseres det tall ukentlig i MSIS-Rapport.

Innsamling: Meldingsskjema fra medisinsk mikrobiologisk laboratorium og behandlende lege.

Utvalg: Alle tilfeller som er meldt av de meldingspliktige sykdommene, også personer bosatt i utlandet som oppsøker lege i Norge.

Tilgang til data: Etter retningslinjene i forskriften.

Soknad sendes til: Nasjonalt folkehelseinstitutt, Postboks 4404 Nydalen, 0403 Oslo.

Web-adresse: www.fhi.no/artikler/?id=28755.

\subsection{Det sentrale tuberkuloseregisteret}

Databehandlingsansvarlig: Nasjonalt folkehelseinstitutt.

Databehandler: Nasjonalt folkehelseinstitutt.

Hjemmel: MSIS og tuberkuloseforskriften av 20. juni $2003 \mathrm{nr} .740$.

Generell beskrivelse: Tuberkuloseregisteret skal bidra til overvåking av forekomsten av tuberkulose i Norge og legge grunnlag for å evaluere virkningen av behandlingstiltak og sikre kvaliteten av disse.

Kjennetegn: Fullt fødselsnummer.

Forste og siste år det finnes data for: 1962-2003.

Antall poster: Totalt ca. 40 000, for tiden registreres ca. 750 personer per år.

Oppdatering: Fortløpende. Årsstatistikk publiseres i MSIS-rapport og legges på Internett.

Innsamling: Meldingsskjemaer fra medisinsk mikrobiologisk laboratorium og behandlende lege og fra Rikshospitalets reseptregister.

Utvalg: Alle meldte tilfeller av tuberkulose, pasienter med atypisk mykobakterieinfeksjon og personer som får forebyggende behandling. Alle som er bosatt i Norge registreres, inkludert asylsøkere.

Tilgang til data: Etter retningslinjer i forskriften.

Soknad sendes til: Nasjonalt folkehelseinstitutt, Postboks 4404 Nydalen, 0403 Oslo.

Web-adresse : www.fhi.no/artikler/?id=28755.

\subsection{System for vaksinasjonskontroll (SYSVAK)}

Databehandlingsansvarlig: Nasjonalt folkehelseinstitutt.

Databehandler: Nasjonalt folkehelseinstitutt.

Hjemmel: SYSVAK-registerforskriften av 20. juni 2003 nr. 739.

Generell beskrivelse: Formålet med SYSVAK er å gi kunnskap om vaksinasjonsdekningen og danne grunnlag for gjennomføring av tilfredsstillende vaksinering på landsbasis. Registeret inneholder opplysninger om barnets personalia, institusjon som har satt vaksinen og fullstendige opplysninger om alle vaksiner som er gitt.

Kjennetegn: Fullt fødselsnummer.

Forste og siste år det finnes data for: Noen fylker fra 1970-tallet, komplett dekningsstatistikk fra 1998 til 2003.

Antall poster: Totalt ca. 15900000 vaksinasjoner.
Oppdatering: Årlig.

Innsamling: Alle helsestasjoner og skolehelsetjenester er pålagt å melde alle vaksiner som hører til Barnevaksinasjonsprogrammet for barn under 18 år. Dette gjelder vaksine som forebygger følgende sykdommer: difteri, kikhoste, kusma, meslinger, poliomyelitt, røde hunder, systemisk Haemophilus influenzae-sykdom, tetanus (stivkrampe), tuberkulose (BCG-vaksine).

Utvalg: Alle meldte vaksiner.

Tilgang til data: Etter retningslinjer i forskriften.

Soknad sendes til: Nasjonalt folkehelseinstitutt, Postboks 4404 Nydalen, 0403 Oslo.

Web-adresse: $\underline{\text { www. fhi.no/artikler/?id=28929. }}$.

\subsection{Reseptbasert legemiddelregister}

Databehandlingsansvarlig: Nasjonalt folkehelseinstitutt.

Databehandler: Nasjonalt folkehelseinstitutt inntil videre.

Hjemmel: Reseptregisterforskriften av 17. oktober 2003 nr. 1246.

Generell beskrivelse: Reseptregisteret inneholder opplysninger om all utlevering av legemidler fra apotek. Formålet med registeret er å kartlegge legemiddelforbruket og gi grunnlag for legemiddelepidemiologisk forskning. Det skal gi myndighetene et statistisk grunnlag for overordnet tilsyn, styring og planlegging og gi legemiddelrekvirenter et grunnlag for internkontroll og kvalitetsforbedring.

Kjennetegn: Pseudonym erstatter fødselsnummer for pasient og HPR-nummer for lege.

Forste og siste år det finnes data for: Opprettet 1. januar 2004.

Antall poster: Forventet antall ca. 26 mill. resepter per år.

Oppdatering: Månedlig

Innsamling: Registreres av apotek, sendes inn månedlig.

Utvalg: Alle resepter og rekvisisjoner som blir ekspedert av apotek registreres.

Tilgang til data: Retningslinjer er under utarbeidelse.

Soknad sendes til: Nasjonalt folkehelseinstitutt, Postboks 4404 Nydalen, 0403 Oslo.

Web-adresse : www.fhi.no/artikler/?id=41766.

\section{Medisinske KVALITETSREgistre}

Medisinske kvalitetsregistre har som formål å sikre kvaliteten av klinisk arbeid. Noen registre har sitt utgangspunkt i diagnostiske grupper, andre registrerer pasienter som gjennomgår visse prosedyrer. Kvalitetsregistre er i hovedsak bygget opp av det helsepersonell som skal rapportere inn data og bruke resultatene, dvs. de er etablert i de medisinske fagmiljøene. Disse registrene bygger på konsesjon fra Datatilsynet og informert samtykke, eventuelt er registeret anonymt. Sosialog helsedirektoratet bevilger årlig en liten sum penger til kvalitetsregistrene og i 2003 var det 110 miljøer/re- 
gistre som søkte om pengestøtte. Registrene som er satt opp i tabellen nedenfor fikk pengestøtte i 2003.

Vi har per i dag ikke oversikt over innhold, geografisk dekning og planer for videre drift for de fleste av disse registrene. Noen av de større registrene er beskrevet nærmere nedenfor.

\subsection{Nasjonalt register for leddproteser}

Databehandlingsansvarlig: Haukeland Universitetssykehus v/ Leif Ivar Havelin.

Databehandler: Haukeland Universitetssykehus v/ Leif Ivar Havelin.

Hjemmel: Konsesjon fra Datatilsynet.

Generell beskrivelse: Registrerer alle innsatte proteser for å oppdage dårlige proteseresultater tidlig, før de blir brukt i stort antall pasienter.

Kjennetegn: Personnummer.

Forste og siste år det finnes data for: $1987-$

Antall poster: t.o.m. 2002: ca. 110000.

Oppdatering: Årlig.

Innsamling: registreringsskjema sendes fra behandlende ortopedisk kirurg.

Utvalg: Alle innsatte leddproteser.

Tilgang til data: Forskere som ønsker tilgang på data må søke. Søknaden behandles av styringsgruppen.

Søknad sendes til: Nasjonalt register for leddproteser, Ortopedisk klinikk, Haukeland Universitetssykehus, 5021 Bergen.

Web-adresse: www.haukeland.no/nrl/.

\begin{tabular}{|c|c|}
\hline Norsk karkirurgisk register (NORKAR) & Kirurgisk avdeling, St. Olavs Hospital \\
\hline Norsk hjerteinfarktregister & Hjertemedisinsk avdeling, St. Olavs Hospital \\
\hline $\begin{array}{l}\text { Register for komplikasjonsregistrering i gastrointestinal } \\
\text { kirurgi }\end{array}$ & Gastroenterologisk seksjon, St. Olavs Hospital \\
\hline Slagregister i Midt-Norge & Medisinsk avdeling, St. Olavs Hospital \\
\hline Nasjonalt register for leddproteser & Ortopedisk klinikk, Haukeland Universitetssykehus \\
\hline Nasjonalt multippel sklerose register & Nevrologisk avdeling, Haukeland Universitetssykehus \\
\hline The Nordic SCI Register & Spinalenheten, Haukeland Universitetssykehus \\
\hline Nasjonalt register for odontologiske implantater & Kjeve-kirurgisk avdeling, Haukeland Universitetssykehus \\
\hline Nasjonalt porfyriregister & $\begin{array}{l}\text { Laboratorium for klinisk biokjemi, Haukeland } \\
\text { Universitetssykehus }\end{array}$ \\
\hline $\begin{array}{l}\text { Register for organ-spesifikke autoimmune } \\
\text { sykdommer(ROAS) }\end{array}$ & Medisinsk avdeling, Haukeland Universitetssykehus \\
\hline Det norske nyrebiopsi-registeret & Haukeland Universitetssykehus \\
\hline Norsk nefrologiregister & Immunologisk institutt, Rikshospitalet \\
\hline $\begin{array}{l}\text { Medisinske kvalitetsregistre ved Senter for revmatiske } \\
\text { sykdommer }\end{array}$ & Revmatologisk avdeling, Rikshospitalet \\
\hline Sentralregister for hjerte-kirurgi i Norge & Thoraxkirurgisk avdeling, Rikshospitalet \\
\hline Nordisk kvalitetsregister for benign gynekologisk kirurgi & Kvinneklinikken, Rikshospitalet \\
\hline BERTE Register for medfødte hjertefeil & Barnehjerteseksjonen, Rikshospitalet \\
\hline Nasjonalt sarkomregister & Avdeling for kirurgisk onkologi, Det Norske Radiumhospital \\
\hline Nasjonal database for registrering av lungekreft - LuCan & Kreftregisteret, Radiumhospitalet \\
\hline OVANOR-prosjektet, Kreftregisteret & Kreftregisteret, Radiumhospitalet \\
\hline Norsk Diabetesregister & Kvinne Barn-divisjonen, Ullevål Universitetssykehus \\
\hline Norsk pacemakerregister (NorPace) & Hjerte-lungesenteret, Ullevål Universitetssykehus \\
\hline Medisinsk kvalitetsregister for sykehusinfeksjoner & Medisinsk divisjon, Ullevål Universitetssykehus \\
\hline Leukemiregisteret & Hematologisk avdeling, Ullevål Universitetssykehus \\
\hline Nasjonalt register for hjertestans utenfor sykehus & $\begin{array}{l}\text { Institutt for eksperimentell medisinsk forskning, Ullevål } \\
\text { Universitetssykehus }\end{array}$ \\
\hline Barnediabetes og Kvalitet & Barnesenteret, Ullevål Universitetssykehus \\
\hline Norsk kvinnelig inkontinensregister & Kvinneklinikken, Bærum sykehus \\
\hline Nasjonal transfusjons-statistikk & Sentrallaboratoriet, Sykehuset Asker og Bærum HF \\
\hline $\begin{array}{l}\text { Overvåking av sykdoms-modifiserende legemidler } \\
\text { (DMARD) i behandlingen av revmatoid artritt og beslektede } \\
\text { sykdommer }\end{array}$ & Revmatologisk avdeling, Diakonhjemmets sykehus \\
\hline SiR Obstetrikk KR & Kvinneklinikken, SiR \\
\hline Nasjonalt Cerebral parese register & Barneseksjonen, Sykehuset i Vestfold \\
\hline Ambustat & Divisjon for akuttmedisin, Sykehuset Østfold HF \\
\hline DiabCare & Medisinsk avdeling, Helse Stavanger HF \\
\hline $\begin{array}{l}\text { JANUS - faglig drifts- og kvalitetsregister ved } \\
\text { Universitetssykehuset Nord Norge }\end{array}$ & Universitetssykehuset Nord Norge HF \\
\hline
\end{tabular}




\subsection{Norsk diabetesregister}

Databehandlingsansvarlig: Dr. med. Geir Joner, Barnesenteret, Ullevål Universitetssykehus.

Databehandler: Dr. med. Geir Joner, Barnesenteret, Ullevål Universitetssykehus.

Hjemmel: Konsesjon av 2002.

Generell beskrivelse: 1) Basis for studier av insidens og prevalens av type 1 diabetes; 2) Epidemiologisk overvåking; 3) Basis for intervensjonsstudier; 4) årsaksforskning type 1 diabetes; 5) Studier på behandlingskvalitet.

Kjennetegn: Fulle persondata, sykdomsstart, kliniske opplysninger, blodprøver, diabetes mellitus 0-18 år.

Forste og siste år det finnes data for: 1989-2003.

Antall poster: ca. 3000.

Oppdatering: Løpende.

Innsamling: Registrering ved landets sykehus.

Utvalg: Alle med nyoppdaget diabetes mellitus 0-18 år.

Tilgang til data: Kvalitetsregisteret eies og drives av Norsk studiegruppe for barnediabetes som vedtar hvilke prosjekter registeret kan brukes til.

Soknad sendes til: NSB v/Daglig leder og sekretær Geir Joner, Barnesenteret, Ullevål Universitetssykehus, 0407 Oslo, geir.joner@ioks.uio.no.

Web-adresse:

www.aker.uio.no/Kompetansesentra/DFS/.

\subsection{Nasjonalt multippel sklerose register}

Databehandlingsansvarlig: Haukeland Universitetssykehus.

Databehandler: Statistiker Jan Aarseth.

Hjemmel: Konsesjon fra Datatilsynet av oktober 1998. Generell beskrivelse: 1. Epidemiologisk overvåkning og registrering av tidstrender i MS-forekomsten. 2. Forskning med muligheter for prospektive studier av genetiske og epidemiologiske forhold. 3. Kvalitetskontroll av medisinske og samfunnsøkonomiske forhold.

Kjennetegn: Fødselsnummer.

Forste og siste år det finnes data for: 2001-

Antall poster: Totalt ca. 2400 pasienter.

Oppdatering: Årlig.

Innsamling: Skjema sendes inn av behandlende nevro-

$\log$.

Utvalg: Alle MS-pasienter i live.

Tilgang til data: Egne retningslinjer er utarbeidet.

Soknad sendes til: Nasjonalt kompetansesenter for multippel sklerose, Nevrologisk avdeling, Haukeland Universitetssykehus, 5021 Bergen.

Web-adresse: www.ms-kompetansesenter.com.

\section{ANDRE VIKTIGE REgISTRE}

Det finnes mange andre personregistre som har vært brukt og brukes aktivt i epidemiologisk forskning. Dette gjelder spesielt de mange registrene fra SSB som knytter seg til sosioøkonomiske forhold, slik som registre over: utdanning, inntekt, landbakgrunn (eget eller foreldrenes fødeland), resultater fra folke- og boligtellinger samt trygdeforhold. Et annet register som har et hovedformål som er av mer administrativ karakter, er Norsk pasientregister som beskrives nærmere nedenfor.

\subsection{Norsk pasientregister}

Databehandlingsansvarlig: SINTEF Helse, Norsk pasientregister.

Databehandler: SINTEF Helse, Norsk pasientregister.

Hjemmel: Konsesjon av mars 1998.

Generell beskrivelse: NPR skal innhente, kvalitetssikre, arkivere og stille til disposisjon pasientdata og statistikk fra virksomheten ved somatiske sykehus og institusjoner innen psykisk helse.

Foreløpig er NPR ikke personentydig. Pasienter kan derfor ikke spores mellom sykehus og år. Imidlertid utredes det for tiden muligheten av å gjøre NPR til et personentydig register og en rapport om dette arbeidet er oversendt til Helsedepartementet i mars 2004.

Kjennetegn: Anonymisert pasientnummer; $1-\mathrm{N}$ ved hvert sykehus i hvert kalenderår.

Forste og siste år det finnes data for: Somatiske sykehus: 1990-2003, voksenpsykiatri: 2000-2003, barneog ungdomspsykiatri: 2003-

Antall poster: totalt 1990-2003 ca. 29 mill. utskrivninger og ca. 4,5 mill. per år.

Oppdatering: Fortløpende.

Innsamling: Sykehusene sender data på $\mathrm{CD} /$ diskett. Utvalg: Alle innleggelser og konsultasjoner ved institusjoner (somatiske og psykiatriske) og poliklinikker.

Tilgang til data: Er i ferd med å utarbeide egne retningslinjer.

Soknad sendes til: Norsk pasientregister (NPR), SINTEF Helse, Olav Kyrresgt 3, 7465 Trondheim. Web-adresse: www.npr.no.

\section{FORSKNINGSREGISTRE VED NASJONALT FOLKEHELSEINSTITUTT}

\subsection{COhort NORway (CONOR)}

Databehandlingsansvarlig: Nasjonalt folkehelseinstitutt.

Databehandler: Nasjonalt folkehelseinstitutt.

Hjemmel: Konsesjon fra Datatilsynet i oktober 2003.

Generell beskrivelse: CONOR er et nettverk av norske helseundersøkelser som er etablert for å oppnå en tilstrekkelig stor og vel karakterisert samling av biologisk materiale og standardiserte helse- og eksponeringsdata fra norske kvinner og menn. Samlingen skal danne grunnlag for forskning om sykdomsårsaker og gi opplysninger om helseforhold i den norske befolkningen. CONOR er et samarbeide mellom Nasjonalt folkehelseinstitutt og de regionale helseundersøkelsene ved de fire universitetene i Norge.

Kjennetegn: Fullt fødselsnummer.

Forste og siste år det finnes data for: 1994-2003. 
Antall poster: Totalt ca. 170000 personer.

Oppdatering: Nye data vil bli samlet inn senere.

Innsamling: I CONOR inngår foreløpig data fra de store regionale helseundersøkelsene gjennomført i perioden 1994-2003 - dvs. Tromsø IV-undersøkelsen, Helseundersøkelsen i Nord-Trøndelag (HUNT 2), Helseundersøkelsen i Hordaland (HUSK), Helseundersøkelsen i Oslo (HUBRO), Oslo II-undersøkelsen, Helseundersøkelsen i Hedmark og Oppland (OPPHED), Tromsø V-undersøkelsen, Helseundersøkelsen i Troms og Helseundersøkelsen i Finnmark (samlet: TROFINN). I tillegg er MoRo II og innvandrerundersøkelsen i HUBRO inkludert. I HUBRO, OPPHED, Tromsø V og TROFINN inngår det også en ren spørreskjemaundersøkelse av 15-åringer, men disse er ikke del av CONOR.

Utvalg: Ulike utvalg basert på fødselsår. Totalt har 313999 personer blitt innkalt til en eller flere CONOR-undersøkelser foreløpig, 173000 har møtt opp. Se www.medisin.ntnu.no/ism/nofe/norepid/2003(1) 11-Engeland.pdf.

Tilgang til data: Retningslinjer er under utarbeidelse. Soknad sendes til: Nasjonalt folkehelseinstitutt, Postboks 4404 Nydalen, 0403 Oslo.

Web-adresse : www.fhi.no/artikler/?id=28138.

\subsection{Mor og barn undersøkelsen}

Databehandlingsansvarlig: Nasjonalt folkehelseinstitutt.

Databehandler: Nasjonalt folkehelseinstitutt.

Hjemmel: Konsesjon fra Datatilsynet i oktober 1996 og september 2003.

Generell beskrivelse: Den norske Mor \& barn undersøkelsen er den største norske investeringen i forskning på årsaker til sykdom hos mor og barn. Undersøkelsen ønsker å få i alt 100000 gravide kvinner og deres partnere med på undersøkelsen allerede fra første ultralyd i ca. 17. svangerskapsuke for så å følge både mødrene og deres barn i lang tid fremover. Hensikten med Mor og barn undersøkelsen er å få mer kunnskap om årsaker til alvorlig sykdom og helseskade.

Kjennetegn: Fullt fødselsnummer.

Forste og siste år det finnes data for: 2000-2003.

Antall poster: $25000+$, mål 100000.

Oppdatering: Har publisert årlige nyhetsbrev.

Innsamling: Spørreskjemaer, blodprøver.

Utvalg: Har som mål å få med alle nyfødte i Norge og deres foreldre.

Tilgang til data: Retningslinjer er under utarbeidelse.

Soknad sendes til: Nasjonalt folkehelseinstitutt, Postboks 4404 Nydalen, 0403 Oslo.

Web-adresse: www.fhi.no/artikler/?id=28384.

\subsection{Tvillingundersøkelsen}

Databehandlingsansvarlig: Nasjonalt folkehelseinstitutt.

Databehandler: Nasjonalt folkehelseinstitutt.

Hjemmel: Konsesjon fra Datatilsynet fra 1992.

Generell beskrivelse: Nasjonalt folkehelseinstitutt driver et stort forskningsprosjekt med fellesbetegnelsen Tvillingundersøkelsen. Dataene samles inn fra tvillinger født 1967-1979, og nye kohorter skal kontaktes for deltagelse. De innsamlede dataene kommer fra to hovedspørreskjemaer, men også fra kliniske delstudier.

Kjennetegn: Fullt fødselsnummer.

Forste og siste år det finnes data for: 1992 og 1998 pluss delstudier.

Antall poster: Totalt 15370 tvillinger født mellom 1967 og 1979.

Oppdatering: Spørreskjemarunder i 1992 og 1998, pluss mindre utvalg.

Innsamling: Tvillingene ble opprinnelig registrert av Medisinsk fødselsregister, spørreskjemarunder og ulike undersøkelser er blitt administrert av Nasjonalt folkehelseinstitutt.

Utvalg: Alle tvillinger født mellom 1967 og 1979 der begge overlevde i minst tre år.

Tilgang til data: Retningslinjer er under utarbeidelse.

Soknad sendes til: Nasjonalt folkehelseinstitutt, Postboks 4404 Nydalen, 0403 Oslo.

Web-adresse: $\underline{\text { www.fhi.no/artikler/?id=42486. }}$.

\subsection{0-åringsundersøkelsene}

Databehandlingsansvarlig: Nasjonalt folkehelseinstitutt.

Databehandler: Nasjonalt folkehelseinstitutt. Hjemmel: Konsesjon fra Datatilsynet fra 1989.

Generell beskrivelse: Nasjonalt folkehelseinstitutt har data fra 450000 menn og kvinner i alder 40-42 år som møtte til hjerte- og karundersøkelser i 1985-99. Disse undersøkelsene ble gjennomført av tidligere Statens helseundersøkelser.

Kjennetegn: Fullt fødselsnummer.

Forste og siste år det finnes data for: 1985-1999.

Antall poster: Totalt ca. 450000 personer.

Oppdatering: Avsluttet.

Innsamling: Skjemaer utfylt av deltakerne, pluss fysiske målinger fra helseundersøkelsene utført av SHUS.

Utvalg: Alle menn og kvinner i alderen 40-42 år ble invitert, rullerende fylke for fylke unntatt Oslo. Deltakelse $52-81 \%$.

Tilgang til data: Retningslinjer er under utarbeidelse. Soknad sendes til: Nasjonalt folkehelseinstitutt, Postboks 4404 Nydalen, 0403 Oslo.

Web-adresse : www.fhi.no/artikler/?id=28183. 